\title{
The National Ignition Facility: The World's Largest Optics and Laser System
}

\author{
E. I. Moses, J. H. Campbell, C. J. Stolz, C. R. Wuest
}

This article was submitted to Photonics West 2003, San Jose, CA, January 25-31, 2003

January 27, 2003

Lawrence

Livermore

National

Laboratory

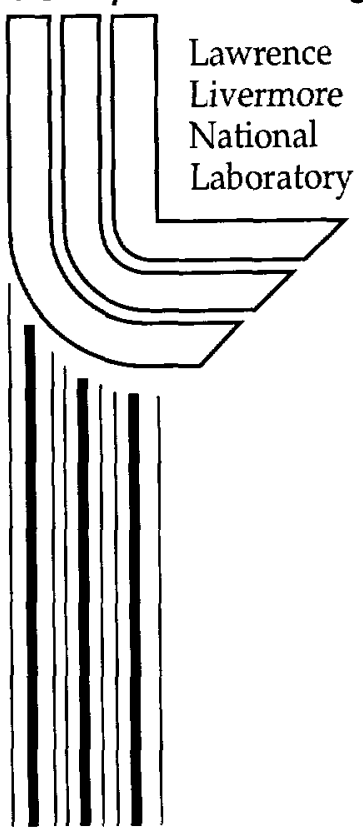




\section{DISCLAIMER}

This document was prepared as an account of work sponsored by an agency of the United States Government. Neither the United States Government nor the University of California nor any of their employees, makes any warranty, express or implied, or assumes any legal liability or responsibility for the accuracy, completeness, or usefulness of any information, apparatus, product, or process disclosed, or represents that its use would not infringe privately owned rights. Reference herein to any specific commercial product, process, or service by trade name, trademark, manufacturer, or otherwise, does not necessarily constitute or imply its endorsement, recommendation, or favoring by the United States Government or the University of California. The views and opinions of authors expressed herein do not necessarily state or reflect those of the United States Government or the University of California, and shall not be used for advertising or product endorsement purposes.

This is a preprint of a paper intended for publication in a journal or proceedings. Since changes may be made before publication, this preprint is made available with the understanding that it will not be cited or reproduced without the permission of the author.

This work was performed under the auspices of the United States Department of Energy by the University of California, Lawrence Livermore National Laboratory under contract No. W-7405-Eng-48.

This report has been reproduced directly from the best available copy.

Available electronically at http://www.doc.gov/bridge

Available for a processing fee to U.S. Department of Energy

And its contractors in paper from

U.S. Department of Energy

Office of Scientific and Technical Information

P.O. Box 62

Oak Ridge, TN 37831-0062

Telephone: (865) 576-8401

Facsimile: (865) 576-5728

E-mail: reports@adonis.osti.gov

Available for the sale to the public from

U.S. Department of Commerce

National Technical Information Service 5285 Port Royal Road

Springfield, VA 22161

Telephone: (800) 553-6847

Facsimile: (703) 605-6900

E-mail: orders@ntis.fedworld.gov

Online ordering: http://www.ntis.gov/ordering.htm

\section{OR}

Lawrence Livermore National Laboratory

Technical Information Department's Digital Library

http://www.llnl.gov/tid/Library.html 


\title{
The National Ignition Facility: The World's Largest Optics and Laser System
}

\author{
Edward I. Moses, John H. Campbell, Christopher J. Stolz, Craig R. Wuest \\ Lawrence Livermore National Laboratory \\ P.O. Box 808 L-466 \\ Livermore, CA 94551
}

\begin{abstract}
The National Ignition Facility, a center for the study of high energy density plasma physics and fusion energy ignition, is currently under construction at the Lawrence Livermore National Laboratory. The heart of the NIF is a frequency tripled, flashlamp-pumped Nd:glass laser system comprised of 192 independent laser beams. The laser system is capable of generating output energies of $1.8 \mathrm{MJ}$ at $351 \mathrm{~nm}$ and at peak powers of $500 \mathrm{TW}$ in a flexible temporal pulse format. A description of the NIF laser system and its major components is presented. We also discuss the manufacture of nearly 7500 precision large optics required by the NIF including data on the manufactured optical quality vs. specification. In addition, we present results from an on-going program to improve the operational lifetime of optics exposed to high fluence in the 351-nm section of the laser.
\end{abstract}

\section{INTRODUCTION}

In 1995, the U.S. Department of Energy established a project to design and build the National Ignition Facility (NIF), a national center for the study of inertial confinement fusion and the physics of matter at extreme energy densities and pressures. The NIF, currently under construction at the Lawrence Livermore National Laboratory (LLNL), is comprised of 192 independent large aperture $(40 \times 40 \mathrm{~cm})$ laser beams that will be used to irradiate and compress deuterium-tritium (D-T) containing targets to conditions of nuclear fusion ignition and burn [1-4]. When complete, the NIF's frequency tripled, Nd:glass laser system will be capable of irradiating fusion targets at $351-\mathrm{nm}$ with an energy of $1.8 \mathrm{MJ}$ and a peak power of $500 \mathrm{TW}[5,6]$. Thus NIF will produce approximately 50 times the laser output energy available in the Nova laser [7], which operated at LLNL from 1983 to 1999 and the Omega Laser currently in operation at the University of Rochester's Laboratory for Laser Energetics [8]. With this output energy, NIF will be able to achieve the long soughtafter goal of liberating more fusion energy output than laser energy input to the D-T target [1].

In addition to fusion ignition experiments, NIF's flexible design will also satisfy a variety of other applications and missions $[3,9,10]$. For example, different combinations of beams can be used to achieve a wide variety of target illumination geometries. Also the NIF pulse generation system allows great flexibility in the output pulse shapes, durations and energies that can be used to irradiate a target. In general, NIF experiments will routinely allow the study of physical processes at temperatures approaching $10^{8} \mathrm{~K}$ and pressures up to $10^{10} \mathrm{MPa}$, conditions that exist naturally only in the interior of stars.

\section{DESCRIPTION OF THE NIF}

The National Ignition Facility is shown schematically in Figure 1. The NIF laser system, the heart of the facility, is comprised of 192 independent laser beams. Each of the 192 beamlines contains a series of flashlamp-pumped, Nd-glass amplifiers operating at $1053 \mathrm{~nm}$. A Pockels cell, having a unique plasma-electrode design, is utilized in combination with a large-aperture $(1-\mathrm{m})$ polarizer to control the number of passes through the amplifier sections. Two large confocal spatial filters ( 30 and $60 \mathrm{~m}$ in length) use pinholes as low-pass filters to remove high spatial frequency noise and image relay the propagating beams to the target chamber. Also a series of mirrors, installed in two large bays called the "switch yards" (Fig. 1), are used to transform the 2-dimensional, planar geometry of the 192 output beams from the main laser into the 3-dimensional spherical configuration required for uniform target illumination. Just prior to entering the target 
chamber, each beam passes through a dual-crystal (KDP/DKDP) frequency converter that converts the fundamental $1053 \mathrm{~nm}$ laser output to $351 \mathrm{~nm}$; this $351 \mathrm{~nm}$ light is then focused onto the target contained within the 10-m diameter vacuum chamber.

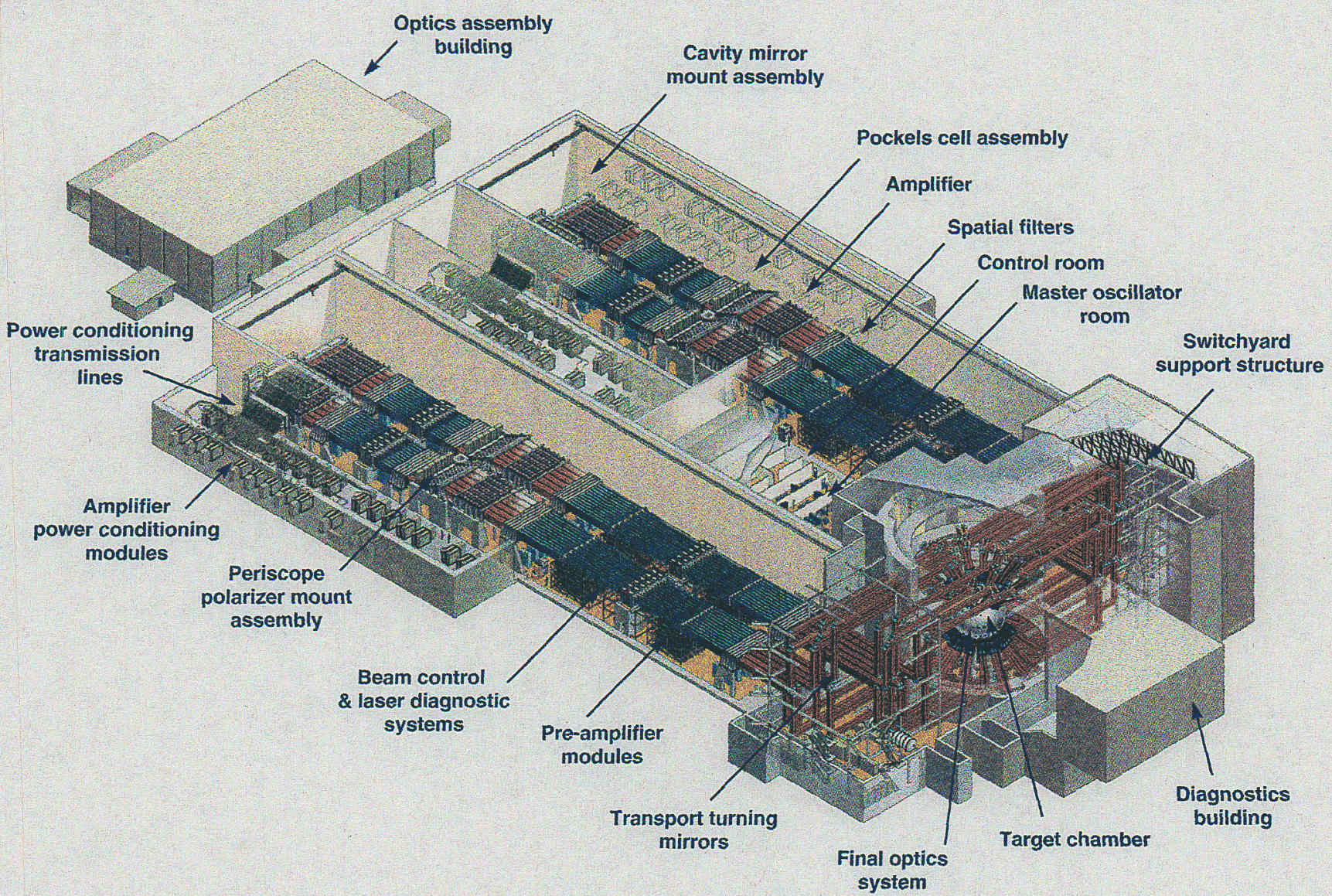

Figure 1: Schematic view of the National Ignition Facility showing the main elements of the laser system. The 10-meter diameter target chamber sets the scale for the facility and is housed in an approximately 10-story high "room". The facility is about $200 \mathrm{~m}$ long (700 ft) and $120 \mathrm{~m}$ wide $(400 \mathrm{ft})$ in the largest dimensions.

The NIF laser system, switchyards, and target area are housed in an environmentally controlled building (Fig. 1). An integrated computer control system is located in the core of the facility to monitor, align, and operate the more than 60,000 control points required for NIF's operation. A large cleanroom facility, the Optics Assembly Building (OAB) is located at one end of NIF and is used to assemble the precision optical and opto-mechanical components that make up the NIF laser system. Robotic transporters ferry the assembled components from the OAB to the laser bays where they are then inserted into the system. Attached to the target chamber end of the facility is the Diagnostics Building that houses areas for target and target diagnostics preparation and also data acquisition and storage.

Figure 2 schematically shows one of the 192 laser beamlines, detailing some of the key technologies that make NIF possible. A NIF laser beam begins with approximately a nano-joule pulse from the master oscillator and a diode-pumped fiber amplifier [11]. This sub-system is designed to provide a variety of tailored pulse-shapes with variable pulse-length and added band-width suitable for the wide range of experiments envisioned for the NIF. The single output pulse from the master oscillator is multiplexed into 48 pulses that are then fed to the preamplifier sections of the laser; here each of the pulses is amplified in two stages. The first stage amplification is accomplished using a diode pumped, Nd:glass regenerative laser amplifier with a net gain of about $10^{6}$. The output from this stage is spatially shaped into a square beam footprint with a "top-hat" (i.e. super-gaussian) intensity profile and then sent to the second pre-amplifier stage. The 
second stage has a net gain of about $2.0 \times 10^{4}$ achieved using a 4-pass flashlamp-pumped, Nd:glass rod amplifier. There are a total of 48 preamplifier systems on NIF, each feeding a "quad" of four beams in the main laser system.

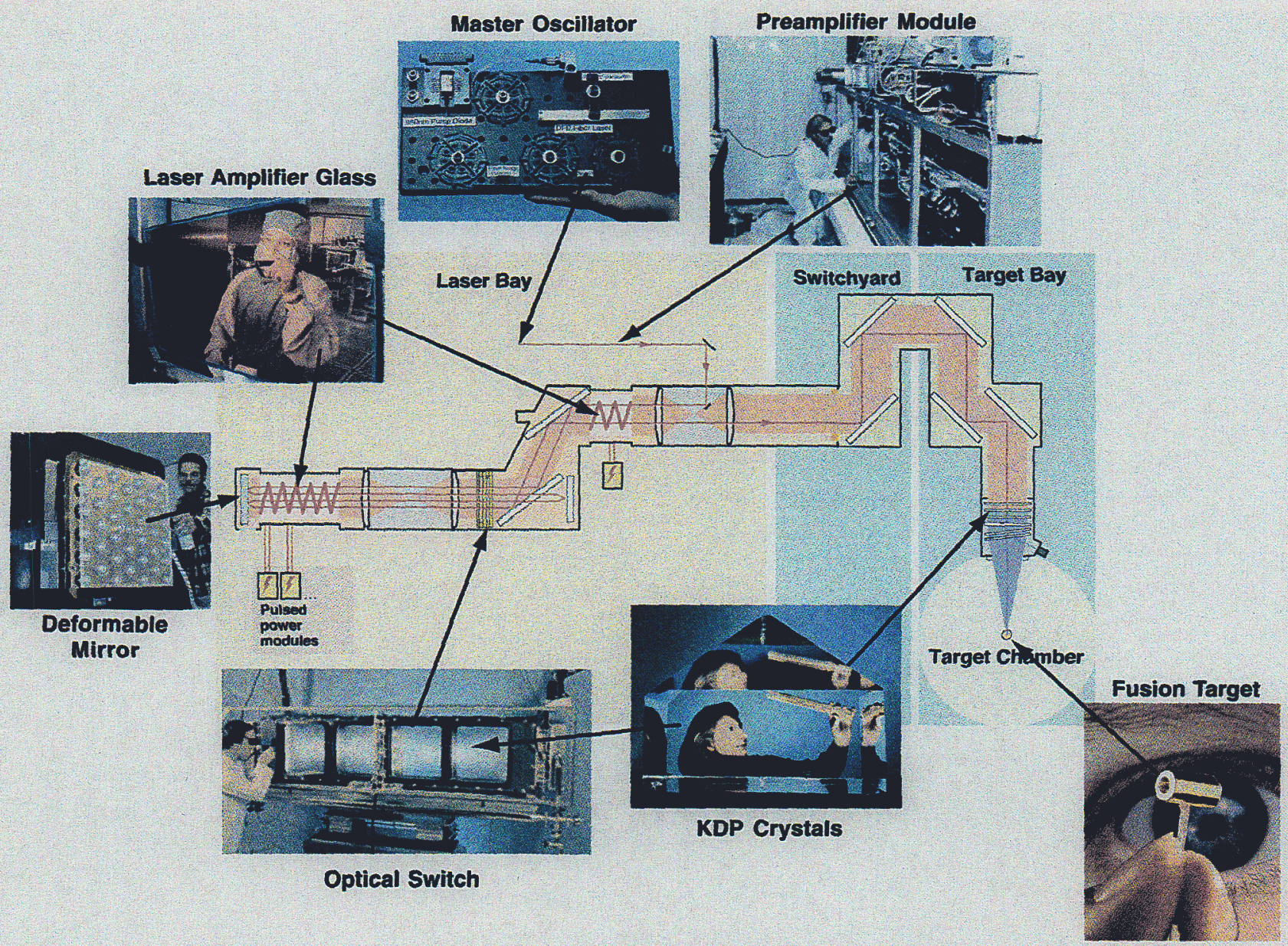

Figure 2: Schematic representation of one of the NIF's 192 laser beam-lines highlighting some of the key technology developments.

A pulse from the preamplifier section enters each large-aperture beamline in the main laser system through a pinhole located at the focal plane of the spatial filter. The beams are amplified in two sections in the main laser (Fig. 2) - the power amplifier, and the multi-pass or main amplifier; these sections respectively contain 5 and 11 flashlamp pumped, Nd-glass laser slabs per beamline. In total, the 192 beamline NIF contains 3072 such slabs, each weighing about 42 kilograms and measuring $46 \mathrm{~cm} \times 81 \mathrm{~cm} \times 4 \mathrm{~cm}$. The slabs are mounted at Brewster's angle to minimize Fresnel surface reflection losses and to enhance the pump efficiency by the surrounding flashlamps. The slabs are stacked four high and two wide to accommodate a "bundle" of eight laser beams (Fig. 3).

The slabs are surrounded by vertical arrays of xenon-containing flashlamps; each lamp is about $4.7 \mathrm{~cm}$ in diameter and $180 \mathrm{~cm}$ in length (Fig. 3). A total of 7680 flashlamps are required for the NIF 192 laser beams. Note that advances in flashlamp and glass amplifier technology allow NIF to operate with less than twice the number of flashlamps required for Nova even though the laser system will produce 60 times more output energy. Electrically, two lamps are connected in series in each of 10 parallel circuits powered by a single NIF Power Conditioning System (PCS) module. The two lamps are driven by approximately $40 \mathrm{~kJ}$ of electrical energy delivered in a 360us pulse with a peak voltage of $60 \mathrm{KV}$ and a peak current of $25 \mathrm{kA}$. The total output energy from all the PCS modules is about $400 \mathrm{MJ}$ making it the highest energy electrical capacitor array ever assembled. 

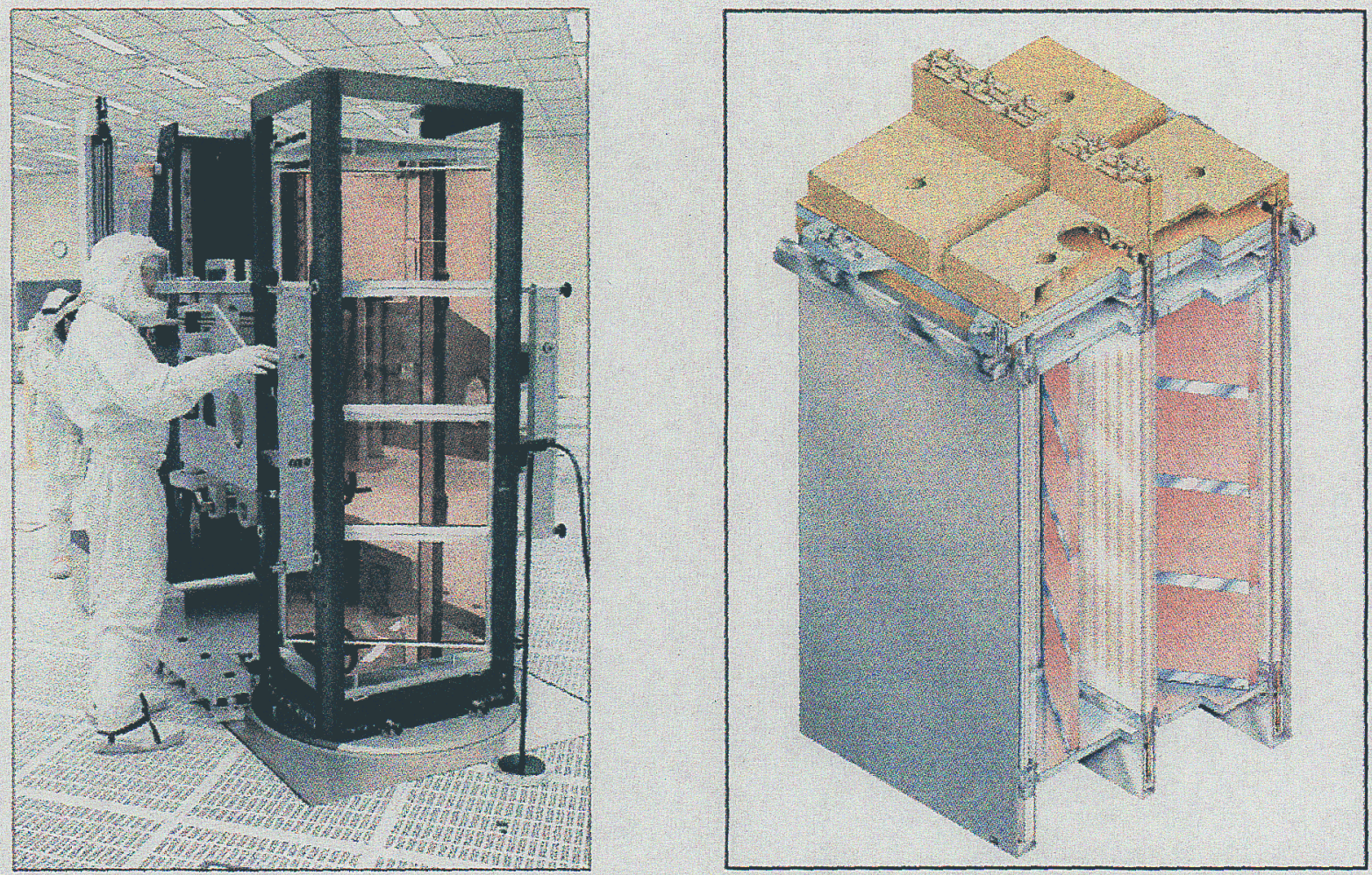

Figure 3: Photograph (on the left) showing assembly of an amplifier slab line-replaceable unit (LRU) containing four Nd:glass slabs mounted one-on-top-of-the-other and set at Brewster's angle. The assembly is being carried out in the NIF Class-100 Optics Assembly Building. The drawing (on the right) shows a cut-away view of the amplifier units and two " $1 \times 4$ " slab LRUs with surrounding flashlamps. The amplifier units are stacked sequentially in groups of 11 long in the multi-pass cavity and 5 long in the power amplifier section (see Figures 1 and 2).

The intense white light from the flashlamps is absorbed by the Nd ions in the phosphate laser glass, pumping electrons to the meta-stable upper laser level [12]. The stored energy in the upper laser level is about $250 \mathrm{~J} /$ liter giving a corresponding small signal gain coefficient of about $0.05 / \mathrm{cm}$ at the $1053 \mathrm{~nm}$ extraction wavelength [11]. At the completion of a shot, the flashlamps and amplifier slabs are cooled using clean dry gas; the cooling rate is designed to allow NIF to be fired once every four hours.

A key component in the laser chain is a plasma-electrode Pockels cell (PEPC) $[11,13,14]$. The PEPC is used in combination with a polarizer to control the number of passes though the main multi-pass amplifier; the NIF uses four passes through the amplifiers, in other words, two round trips within the cavity. Each of the PEPC apertures contains a 1$\mathrm{cm}$ thick KDP plate cut normal to the crystal z-axis. The crystal plate is sandwiched between two gas glow-discharge plasmas that have sufficiently low electron density so as not to absorb, reflect or diffract the beam as it passes through the cell. The conductivity of the plasmas is high enough to allow the opposing crystal surfaces to charge to the switching voltage in about 100 nanoseconds. The plasma uniformity gives high switching efficiencies, typically better than $99 \%$. The inset in Figure 2 shows the four-aperture PEPC in operation; the PEPC is oriented vertically in a single unit when inserted into the NIF beampath.

All major laser components are assembled in clean, pre-aligned modules called line-replaceable units or LRUs [11]. These LRUs contain the precision large optics, i.e. laser slabs, mirrors, polarizers, lenses, crystal plates, and windows. All LRUs are designed to be robotically installed into the NIF "exoskeleton" (called the beampath-infra-structure or BIS). This structure also maintains the high level of cleanliness required to reduce or eliminate laser-induced damage at 
high operating fluences. As of January 2003, the installation, integration, and commissioning of the clean beampath infrastructure is about $50 \%$ complete.

The NIF target area contains a 10-meter diameter vacuum target chamber (Figure 4). The target chamber contains the requisite number of laser entry ports to accommodate the 192 laser beams as well as over 100 ports for diagnostic instrumentation and target insertion. Each laser port allows four laser beams (a "quad") to enter the chamber. Mounted on the entry port is a precision optical assembly that containing the dual crystal frequency converters and final focusing optics for each of the four beams. Also included in this optical assembly are four full-aperture diffraction gratings (one per beam), used to diffract about $0.2 \%$ of the beam energy to a diagnostic package. The last optic in each NIF beamline is a relatively low-cost fused silica debris shield that blocks target debris from hitting the more expensive optics contained in the final optics assembly. Each quad of beams can be isolated from the target vacuum using a large, remotely operate value.

Further details of the NIF design and its key laser and other system components can be found elsewhere [11].

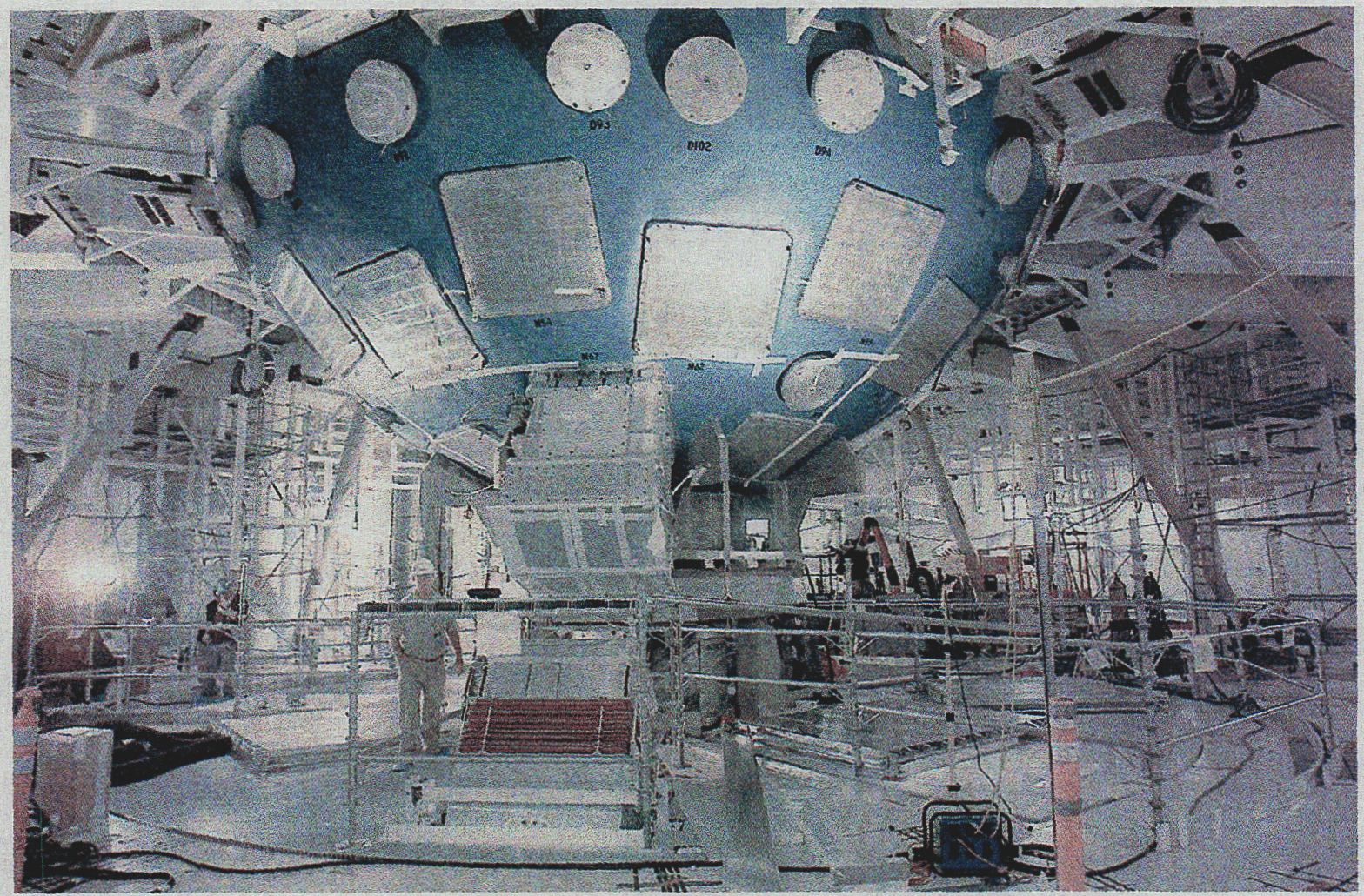

Figure 4: Photograph of the lower third of the NIF 10-meter diameter target chamber showing the numerous square ports where "quads" of four beams enter the chamber. Each quad of beams enters through a Final Optics Assembly (FOA), the first of which is shown just above and to the right of the man in the photo. The beam tubes that will eventually connect to the FOA can be seen penetrating through the floor in their retracted configuration. Also shown are numerous circular entry ports on the target chamber; these are for target diagnostics.

\section{MANUFACTURING NIF LARGE OPTICS}

To a large extent the development of high-energy and high-peak-power laser systems has been made possible by corresponding developments in optical materials and optical manufacturing technology [15]. For example, the NIF, which when complete will be the world's largest optical system, uses more than 7500 precision optics between 0.4 to $1.0 \mathrm{~m}$ in size. This includes $3072 \mathrm{Nd}$-doped phosphate glass laser slabs, 960 fused silica aspheric lenses, 960 fused silica 
windows, 1600 multi-layer dielectric mirrors and polarizers, 192 diffraction gratings, 192 phase plates and 576 KDP plus DKDP crystal plates (see Fig 5). In addition, approximately 15,000 smaller precision optics are required for the diagnostic and the pulse generation and pre-amplifier subsystems.

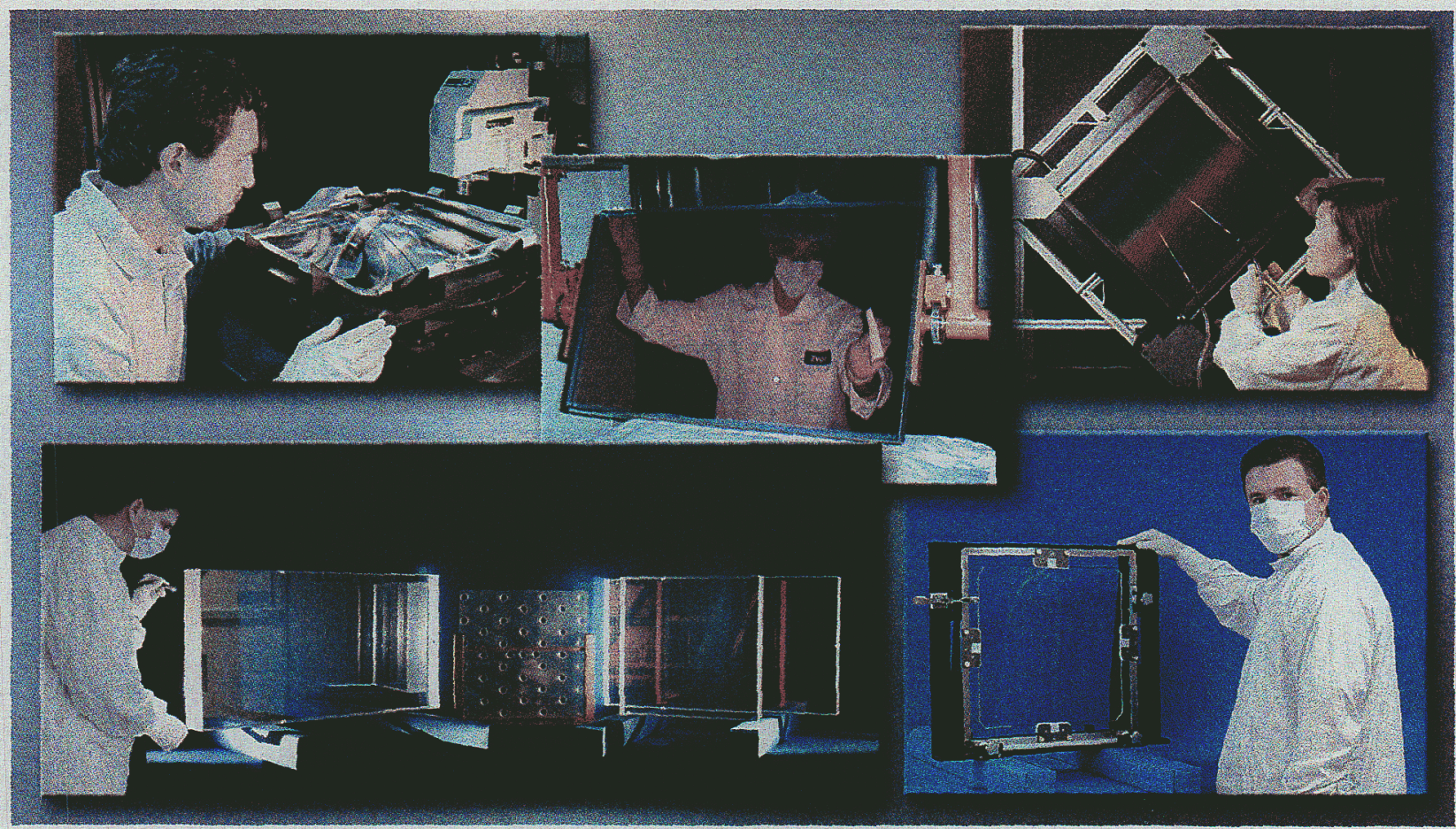

Figure 5: Examples of large optics used on NIF. Clockwise from upper left: fused silica wedged focus lens, neodymiumdoped phosphate laser glass slab, fused silica beam sampling grating, KDP frequency conversion crystal, and multi-layer dielectric coatings (on BK-7 substrates) that comprise the mirrors and polarizers.

Among the many challenges in designing and building NIF have been the research and development on optical materials, optics design, and optics manufacture needed to achieve the high output energies and precision beam quality within a fixed cost envelop. Many of the crucial optical technologies required for the NIF were demonstrated in 1994-95 on "Beamlet", a single-beam prototype of a NIF laser beam [16]. However, to meet the demands of NIF for compact design, improved performance plus reliable, rapid and low-cost manufacturing required significant additional development. Therefore, beginning in 1995 we initiated a multi-year effort to further improve NIF optical materials and develop new manufacturing technologies. As a result of this effort we can now manufacture NIF precision large optics

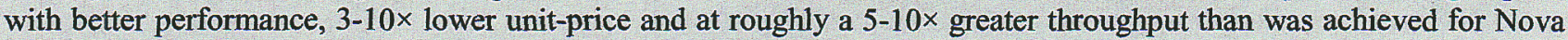
plus Beamlet combined. Some of these improvements include:

- New laser glass compositions [12] and advanced optical glass melting methods [17,18]

- Novel glass asphere and flat fabrication technologies using state-of-the-art deterministic figuring methods $[15,19,20]$

- $10 \times$ faster KDP/DKDP crystal growth methods and novel high-capacity precision crystal finishing machines $[15,21]$

- Laser damage resistant dielectric mirrors and polarizers manufactured to stringent multi-wavelength reflection and transmission specifications [22-25]

- Environmentally stable, laser damage-resistant, sol-gel anti-reflection coatings $[15,26]$

- Novel diffractive grating and continuous phase plate design and fabrication methods.

To develop the NIF optical materials and advanced manufacturing methods, LLNL has partnered with a number of key optical vendors across the world (Fig. 6). This approach builds on a 25 -year tradition of closely working with the private 
sector to develop and manufacture the optics needed for the high-energy laser systems constructed at LLNL, specifically: Beamlet (1991-94), Nova (1980-85), Novette (1983), Shiva (1974-76), Argus (1973) and Janus (1971).

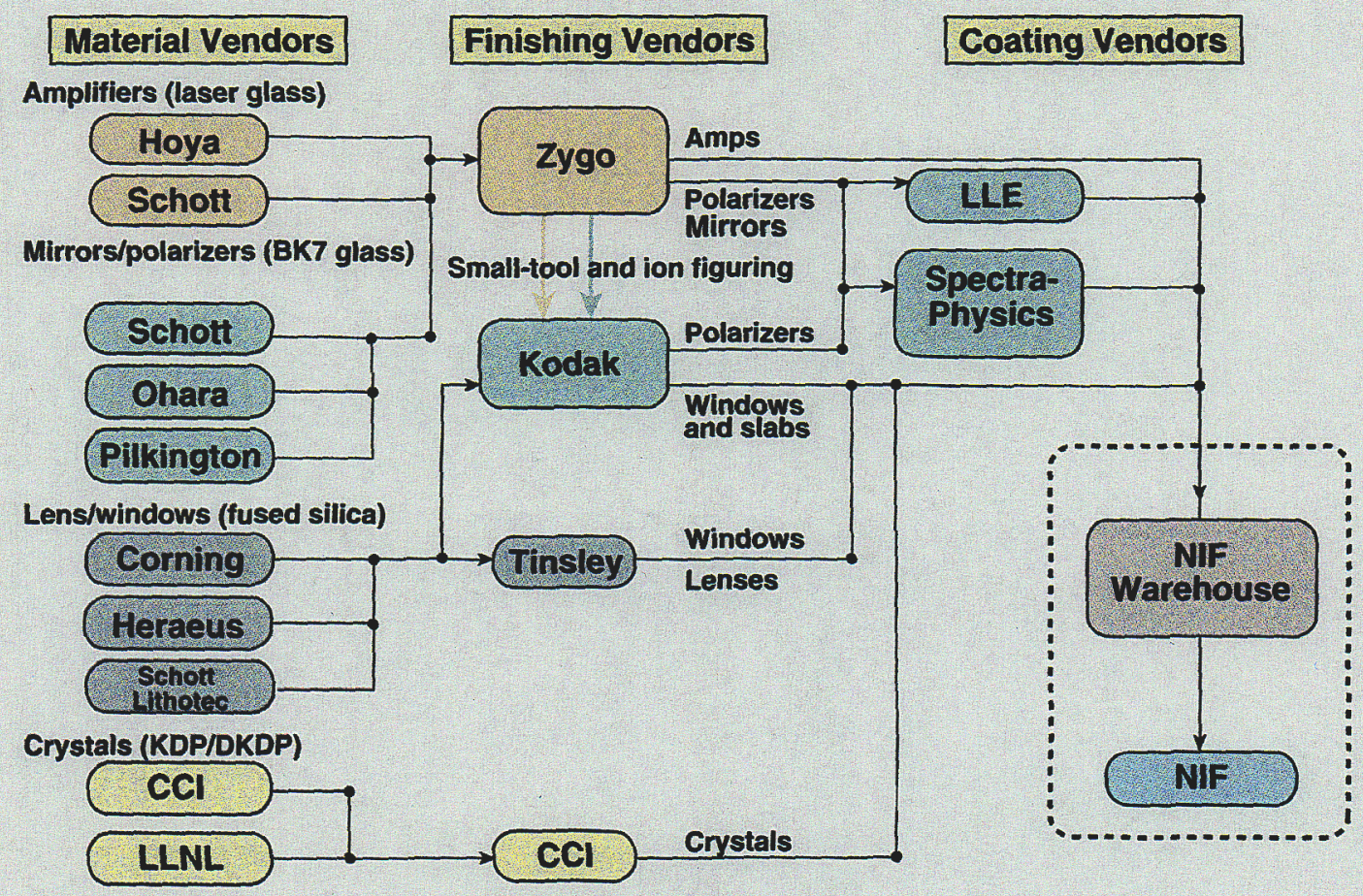

Figure 6: The NIF optics are manufactured by the group of well-known optical vendors shown above. They supply either (1) raw glass or crystal blanks, (2) finished flats and/or aspheres or (3) multi-layer optical coatings for mirror and polarizers. The workflow is indicated by the arrows on the chart. The completed optics are shipped to a warehouse near the NIF where they are stored until being cleaned, assembled and installed in the laser beampath.

In general, our approach to large optic manufacturing involves four steps: (1) development, (2) design and construction of manufacturing facilities, (3) start-up and "pilot" production and (4) full production. The development stage includes not only the development of the optical materials and advanced manufacturing tools and processes (the results of which are described in publications listed in the reference section) but also the advanced metrology tools needed to test and verify the performance of the finished optics. For example, to produce the NIF optics required the development, construction and installation of ten 24-inch phase-measuring interferometers at the various manufacturing facilities. The interferometers are used to test the full-aperture transmitted or reflected wave-front quality of each manufactured optic. In addition, four custom high-power-laser scanning systems were developed and installed for full aperture testing of laser glass and dielectric coatings for potential damage causing defects [27]. Also precision, scanning photometers have been installed at the NIF coating vendors and at LLNL to QA the full-aperture transmission and reflection performance of the coated optics. Finally, precision crystal alignment tools have been developed and fielded to verify that the frequency conversion crystals are fabricated to the prescribed phase matching angles.

During the second step of the NIF manufacturing development effort (design and construction of optics manufacturing capabilities) we funded the construction and installation of approximately $\$ 100 \mathrm{M}$ of new optics manufacturing space and advanced processing equipment. These state-of-the-art facilities were then commissioned by the third step (i.e. pilot operations), during which a small percentage $(5-10 \%)$ of the required optics were manufactured to shake-down and troubleshoot the process and verify that performance and cost goals could be met.

The NIF large optics are now at the final step: full production. We are currently manufacturing optics at a combined rate of nearly 100 per month; this meets the schedule of 2007 for completing production for all the optics required for the NIF 192 beam lines. 
The quality of the optics produced for NIF has surpassed our expectations; many are significantly better than the specification giving added design margin to the lisser system. Thene are many different specifications for the various NIF opties and therefore it is beyond the seope of this papher to present perfonmanse resutts for all of these. Instead results are presented for several of the wavefront and sufface spectfications that apply to all the glass optics (fused silica, laser glass slabs and 8K-7 stbstrates) being nanutactured. The UIF opties wavefront and surface specifications are defined for different spatial scale lengths as follows (at $633 \mathrm{mn}$ ) (28)

- Peak-to Valliey $(W 3)$ and RMS gradient $(1996 \mathrm{~cm})$ over spatial seales greater than $33 \mathrm{~mm}$

- Power speetral density over a spatial scale from 2.5 to 33 mm(DSDI). Rq $<1.8 \mathrm{~mm}$

- Power spectral density over a spatial scale from 0.12 to $2.5 \mathrm{~mm}$ (PSOM). Rq $<1.1 \mathrm{~nm}$

- Micro-roughness over spatial periods $0.01-0.12 \mathrm{~mm}:<0.4 \mathrm{~mm}$ (glass) or $41.0 \mathrm{~nm}$ (crystals)

The specifications over the longer spatial periods $(>2.5$ men) are measured over the entire eftective aperture of the optic using the $24^{\prime \prime}$ phase-measuring interferometers with mege pixel cameras in order to obtain adeguate resolution. Specifications over shont spatial periods ( $(2.5 \mathrm{~mm}$ ) are measured on micro phase- measuring inferferometers al nine subapertures of the optic to obtain a representative sampling.

Figure 7 shows results from metsurements of three key wave-front parameters for the NIF large glass opties produced to date. All of the chats are histograms and use the same format, the abseissa stows the specification in a normalized sense and the ertinate shows the number of completed optics that fall in a given range of the specification. Optics falling below 1 on this nornalized $x$ axis scale sre better than the opecification. The histograms show peak-to-valley (PV) and RMS gradient over spattal scales greater than $33 \mathrm{~mm}$ and power spectril densities over 2.5 to 33 mm (PSDH). Both the PV and PSDI curves show that on average the optics are aboul $30.50 \%$ better than the specification. The RMS gradient data are also, on average, better than specification. The thet effect is an added perfornime margin for the NIF over that specified by the destgn.

Several of our vendors are using one or more deterministic finishing techniques for localized figuring of opties with material inhomogeneties that camnot be comected by the standard planetary polishing methods. The results have been very siccessful. For example, a snall percentage of amplifter slabs require a ninor correction of the P-V and RMS gradient valtes; results show that these vetues are typically improved an average of three-fotd from a just single small. lool potisting iteration, without degrading the PSD. Simitaity, large (1 - meter) BK-7 polarizer substrates conrected by a detezministic ion figuning process show an 8-fold retuction in the as-poltshed PVV and RMS values and a two-fold improvernent in PSD values.

\section{MPROVINC OTTICS WITUTME}

Alfhough there are many technological and scientific challenges to develoging optes for high-power-lasers, perhaps the mast critical challenge has been the reduction and, where possible, elimingtion of laser-induced damage. This is a continuing challenge because as new laser-damage-reststant optical naterals and fabricafton technotogies are developed, laser designers increase the system operating enetgies and powers to the linits of these new materials 29 . 31). The redson is both economically and scientifically driven, the higler the dannage resistance of the eptics, the longer the lifetine of the optic as fluence levels becorne nore stressing, and the greater the laser output energy that can be achieved for a given cost. In this section we focus on aew methods developed for MF to improve the laser damage resistance of glasses and polished glass surfaces. Note that simifar work is also 0 - going to improve the damage resistance of optical contings $[22-25)$ and non- linear crystats ( $(10 \%$ and DKOD) $[21,32]$

To better understand laser-induced damage in optical glasses reguires an understanding of (1) the mechanismas for light interaction with bulk glass and glass surfaces at high intensity and sthon pulse length (fs to ns), (2) the chemistry and phystes of glass surfaces as modiffed by finishing ( polishing'). (3) glass fracture and fracture analysis, and (4) optical fadiation-induced defect formation in glass across a broad fange of cacrgies. Some key findings related to the specific applicafion af optical glasses on NIF are summarized in the following sections. Note. laser-induced damage to optical materiats has been a stubject of intense stuky for nore thin 30 years. An anmul sceentifie symposiun, beginting in 1971 and extending to today, provides a comprehensive compilation of scientifie work in this area (33), ) 
The quality of the optics produced for NIF has surpassed our expectations; many are significantly better than the specification giving added design margin to the laser system. There are many different specifications for the various NIF optics and therefore it is beyond the scope of this paper to present performance results for all of these. Instead results are presented for several of the wavefront and surface specifications that apply to all the glass optics (fused silica, laser glass slabs and BK-7 substrates) being manufactured. The NIF optics wavefront and surface specifications are defined for different spatial scale-lengths as follows (at $633 \mathrm{~nm}$ ): [28]

- Peak-to-Valley $(\lambda / 3)$ and RMS gradient $(\lambda / 90 / \mathrm{cm})$ over spatial scales greater than $33 \mathrm{~mm}$

- Power spectral density over a spatial scale from 2.5 to $33 \mathrm{~mm}$ (PSDI): $\mathrm{Rq}<1.8 \mathrm{~nm}$

- Power spectral density over a spatial scale from 0.12 to $2.5 \mathrm{~mm}$ (PSDII): $\mathrm{Rq}<1.1 \mathrm{~nm}$

- Micro-roughness over spatial periods $0.01-0.12 \mathrm{~mm}$ : $<0.4 \mathrm{~nm}$ (glass) or $<1.0 \mathrm{~nm}$ (crystals)

The specifications over the longer spatial periods $(>2.5 \mathrm{~mm})$ are measured over the entire effective aperture of the optic using the 24" phase-measuring interferometers with mega-pixel cameras in order to obtain adequate resolution. Specifications over short spatial periods $(<2.5 \mathrm{~mm})$ are measured on micro phase-measuring interferometers at nine subapertures of the optic to obtain a representative sampling.

Figure 7 shows results from measurements of three key wave-front parameters for the NIF large glass optics produced to date. All of the charts are histograms and use the same format; the abscissa shows the specification in a normalized sense and the ordinate shows the number of completed optics that fall in a given range of the specification. Optics falling below 1 on this normalized $\mathrm{x}$-axis scale are better than the specification. The histograms show peak-to-valley (PV) and RMS gradient over spatial scales greater than $33 \mathrm{~mm}$ and power spectral densities over 2.5 to $33 \mathrm{~mm}$ (PSDI). Both the PV and PSDI curves show that on average the optics are about $30-50 \%$ better than the specification. The RMS gradient data are also, on average, better than specification. The net effect is an added performance margin for the NIF over that specified by the design.

Several of our vendors are using one or more deterministic finishing techniques for localized figuring of optics with material inhomogeneities that cannot be corrected by the standard planetary polishing methods. The results have been very successful. For example, a small percentage of amplifier slabs require a minor correction of the P-V and RMS gradient values; results show that these values are typically improved an average of three-fold from a just single smalltool polishing iteration, without degrading the PSD. Similarly, large (1-meter) BK-7 polarizer substrates corrected by a deterministic ion figuring process show an 8-fold reduction in the as-polished P-V and RMS values and a two-fold improvement in PSD values.

\section{IMPROVING OPTICS LIFETIME}

Although there are many technological and scientific challenges to developing optics for high-power-lasers, perhaps the most critical challenge has been the reduction and, where possible, elimination of laser-induced damage. This is a continuing challenge because as new laser-damage-resistant optical materials and fabrication technologies are developed, laser designers increase the system operating energies and powers to the limits of these new materials [2931]. The reason is both economically and scientifically driven; the higher the damage resistance of the optics, the longer the lifetime of the optic as fluence levels become more stressing, and the greater the laser output energy that can be achieved for a given cost. In this section we focus on new methods developed for NIF to improve the laser damage resistance of glasses and polished glass surfaces. (Note that similar work is also on-going to improve the damage resistance of optical coatings [22-25] and non-linear crystals (KDP and DKDP) [21,32]

To better understand laser-induced damage in optical glasses requires an understanding of (1) the mechanisms for light interaction with bulk glass and glass surfaces at high intensity and short pulse length (fs to ns), (2) the chemistry and physics of glass surfaces as modified by finishing ("polishing"), (3) glass fracture and fracture analysis, and (4) optical radiation-induced defect formation in glass across a broad range of energies. Some key findings related to the specific application of optical glasses on NIF are summarized in the following sections. (Note: laser-induced damage to optical materials has been a subject of intense study for more than 30 years. An annual scientific symposium, beginning in 1971 and extending to today, provides a comprehensive compilation of scientific work in this area [33].) 

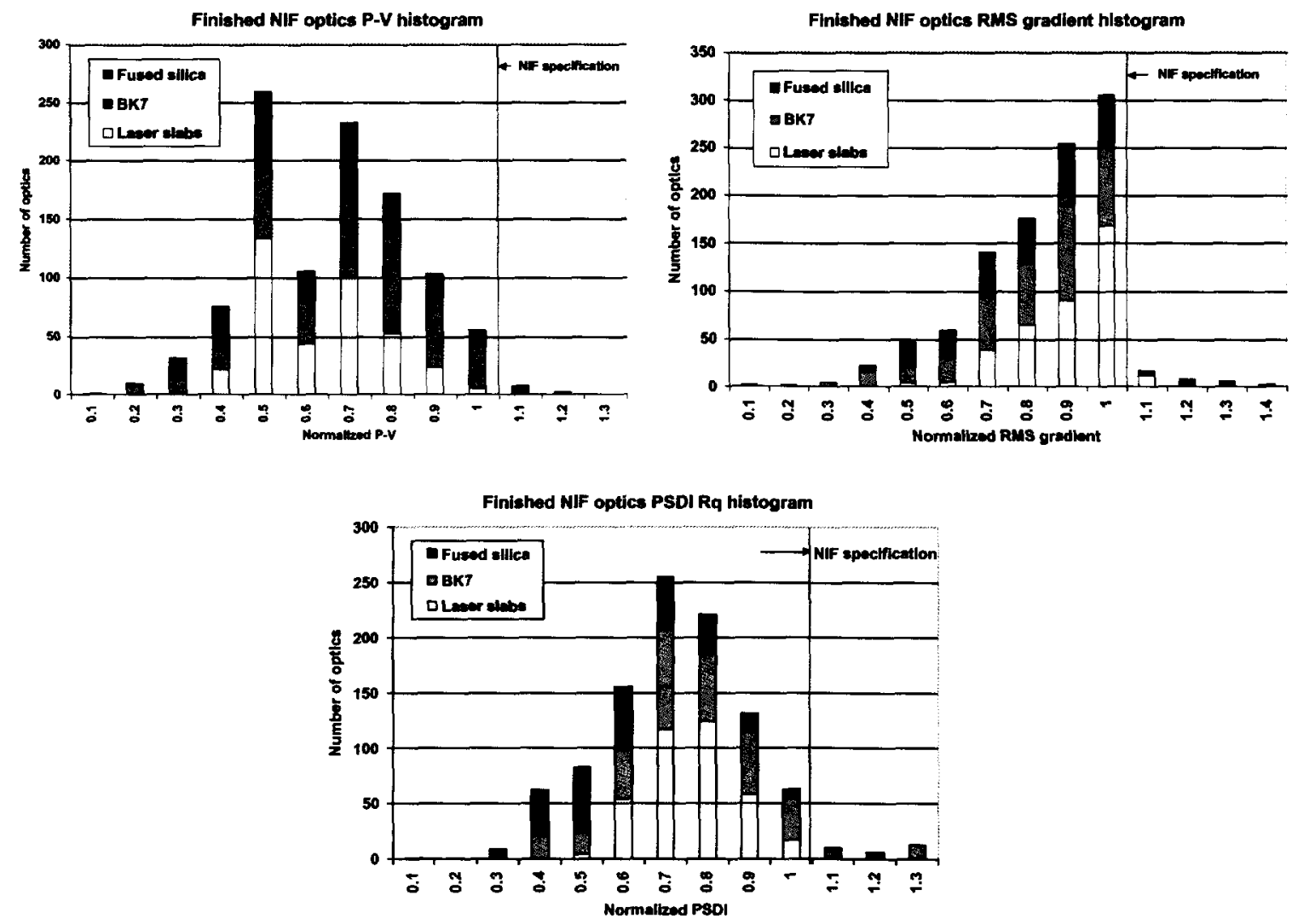

Figure 7: Histograms of transmitted and reflected wavefront data for finished fused silica, BK7, and laser glass optics (see text for details).

\subsection{Improving the internal damage threshold of optical glasses}

Laser damage to the bulk (interior) of a glass optic is caused by multi-photon ionization and avalanche breakdown [34]. The fluence necessary to achieve breakdown is greater than several hundred joules $/ \mathrm{cm}^{2}$ for lasers operating at energies well below the material band gap and at ns pulse lengths. Therefore the glass surface generally damages first [30]. The exceptions are damage due to self-focusing at high intensities and long intra-glass optical path-lengths and damage due to bulk-impurities (e.g., inclusions). To avoid self-focusing damage, laser designers use optical glasses having a low non-linear index, $\mathrm{n}_{2}$, and also design the system with the minimum possible glass optical path-length, particularly in the high fluence, UV section of the laser.

Apart from self-focusing, the major cause of bulk damage to glasses is absorbing inclusions. In most cases the inclusions originate from the melting container materials, particularly platinum and refractory oxides. Platinum-lined melting vessels are required to prepare glasses with the high optical homogeneity needed for laser applications, however this leads to trace concentrations of microscopic Pt metal particles in the glass [18,35]. The presence of high levels of Pt inclusions typically found, for example, in silicate, borosilicate, and fluorophosphates make these glasses unsuitable for high-energy laser applications. In the late 80's LLNL worked with two vendors to develop Pt inclusion-free laser glasses using a suite of phosphate-based glass compositions [35-38]. We found that platinum inclusions could be prevented by carefully controlling the melting conditions such that $\mathrm{Pt}$ particles dissolve into the phosphate glass matrix. Specifically, phosphate glasses were chosen because of their inherently high Pt solubility $(\sim 1000 \mathrm{ppm})$ when melted under oxidizing conditions. Platinum in the dissolved (i.e. ionic) form in the glass does not cause damage.

The other glass chosen for use in the high fluence sections of NIF is fused silica. Presently we use two different grades of fused silica on the NIF. One grade is made by a more conventional CVD deposition process [39] and is acceptable for 
use in the $1053 \mathrm{~nm}$ section of the laser system. However, a small number of refractory oxide inclusions and other defects in this material make it unacceptable for use at 351-nm [40]. For the 351-nm section we use a second, improved grade of fused silica developed for the next generation of lithographic applications; this material can be manufactured free of refractory inclusions and in large sizes $\left(>40 \times 40 \mathrm{~cm}^{2}\right)$ with high optical homogeneity [41,42].

\subsection{Laser-induced damage to optical glass surfaces}

Recent pioneering work has been carried out leading to a theory of surface damage to transparent dielectric materials that, when compared with recent experimental results accurately predicts the surface damage threshold for silicate glasses over approximately five orders of magnitude in pulse length [34]. In the long-pulse region ( $\left.t_{p}>20 \mathrm{ps}\right)$ laser damage is characterized by linear absorption and heating of conduction band electrons followed by transfer of energy to the lattice; this in turn leads to heating and phase changes (melting and vaporization) of the material. At shorter pulse lengths $\left(t_{p}<20\right.$ ps) the onset of damage can be theoretically described by the generation of free electrons via multiphoton ionization that are then rapidly heated in the oscillating electric field leading to collisional (avalanche) ionization [34]. The electron heating is so fast that the energy transfer rate to the lattice is slow and rapid plasma formation and material ablation result.

The NIF operates in the ns pulse length regime so the long pulse limit for damage applies. The optical absorption leading to laser-induced surface damage is dominated by residual nano- to micro-scale defects and impurities on the optic surfaces left by the polishing process [43-44]. Our recent work has focused on quantifying the onset and extent of laser damage by various surface defects as well as seeking ways to reduce or eliminate them. For example, several studies have quantified the impact of surface scratches and other visible defects on laser fluence limits [45]. In addition, work has focused on understanding damage initiation and growth on $\mathrm{SiO}_{2}$ surfaces visibly free of defects [46]. It has been shown that the initial damage sites are usually less than $50 \mu \mathrm{m}$ in diameter and remain small at fluences less than about $5 \mathrm{~J} / \mathrm{cm}^{2}$ at $3 \mathrm{~ns}$ and $351 \mathrm{~nm}$. At fluences greater than this the damage sites grow exponentially with the number of laser shots.

Our approach to reduce and ultimately eliminate residual contaminants and sub-surface defects left from the polishing process is to apply one or more novel "post-processing" techniques. One such technique is magnetorheological finishing (MRF) [47-51]. In contrast to conventional polishing, which relies on a normal load applied to an abrasive particle to cause material removal, MRF uses a shear force. In brief, the process makes use of a slurry containing ferromagnetic (iron carbonyl) particles to create a magnetically-induced synthetic polishing surface. The slurry also contains standard polishing components (e.g., ceria, diamond) that drive the material removal process.

We have found a dramatic reduction in visible sub-surface damage for fused silica optics first finished by conventional means and then treated with an MRF post-processing step followed by hydrofluoric acid etching (Fig. 8) [52]. The HF etch removes any residual UV absorbing ferromagnetic contaminants left from the MRF process.

A second post-processing step involves laser conditioning of the surface by raster scanning the full optic surface at increasingly higher laser fluences to a point just below damage onset. Laser conditioning was originally developed to improve the damage resistance of multi-layer dielectric coatings [22,23,53] and KDP crystals [54,55]. For optical glasses, it is believed that laser conditioning gently removes surface or near-surface defects giving negligible damage that does not grow at high fluences [56].

Although MRF post-processing followed by acid etching and laser conditioning has been shown to dramatically reduce damage density, these steps do not entirely eliminate all damage. Recent work at LLNL has demonstrated a method for initiating and then repairing any residual damage sites left on an optic surface [57]. The initiation is accomplished by simply scanning the optic at high fluence with a small diameter laser beam at $351 \mathrm{~nm}$. These initiated damage sites are then "repaired" by ablatively removing the damaged material using a timed exposure to $10.6 \mu \mathrm{m} \mathrm{CO}_{2}$ laser light. Subsequent testing shows that these "repaired" sites do not experience further damage or damage growth [57]. Also the ablated sites are small and do not produce diffraction-induced intensity modulations on the down-stream optics. 


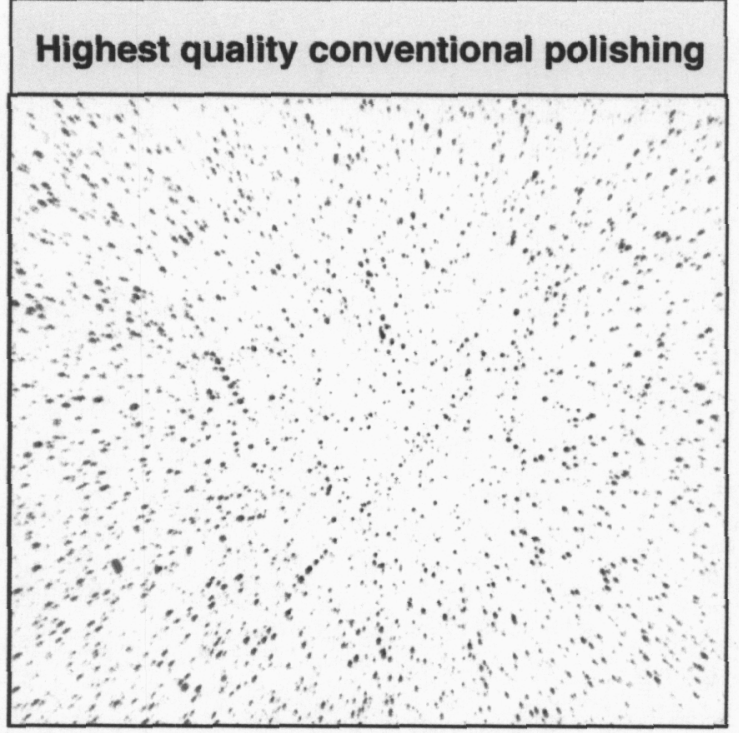

|

$100 \mu \mathrm{m}$

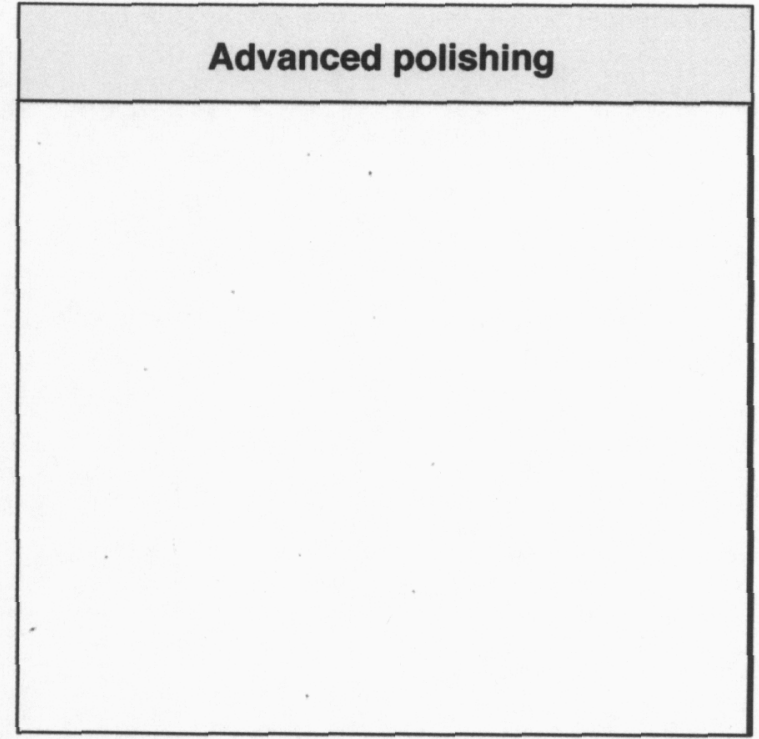

| IIII|III| $100 \mu \mathrm{m}$

Figure 8: Negative image showing the residual sub-surface defect sites on a polished $\mathrm{Si}_{2}$ surface after conventional polishing (left) and then post-process polishing by MRF (right). The sites are made visible by first etching the glass surface and then side-lighting the optic with a white-light source.

\section{FUTURE DIRECTIONS FOR NIF AND HIGH ENERGY, HIGH POWER OPTICS}

NIF currently has over one half of its beampath infrastructure in place (Fig. 9) and component installation and laser commissioning have begun. In June 2002 the first preamplifier module was installed in the Laser Bay and use to demonstrate amplification master oscillator pulses to the required joule level. At the end of November 2002 we installed all the optics and opto-mechanical systems for the first four laser beams (a quad). In December 2002 we successfully achieved our first significant laser performance milestone by firing this quad of beams to produce a total output of $43 \mathrm{~kJ}$ at $1053 \mathrm{~nm}$ with a beam-to-beam energy balance of less than 5\%. Our next milestone, scheduled for June 2004, is to propagate this quad of $1053 \mathrm{~nm}$ beams through the switchyard and into the target chamber where the $1053 \mathrm{~nm}$ light will be converter to 351-nm and focused to target chamber center. Completion of all 192 laser beams is scheduled for September 2008.

Research is also underway to explore how NIF can be used to generate high-energy petawatt (HEPW) pulses. Our goal is to generate petawatt power levels with $10-100 \times$ greater energies than the $0.5 \mathrm{~kJ}$ produced by the first high-energy petawatt-class laser pioneered on Nova in the mid-90's. NIF's flexible, modular design allows a number of different technologies for pulse injection and final high power optics to be fielded and tested. HEPW beams can be used to create higher power x-ray back-lighters, explore new fusion ignition concepts, and to study plasma physics at extremely large electromagnetic fields. The available mega-joule energy of NIF together with the amplification bandwidth of neodymium glass defines an ultimate power capability approaching the exa-watt level $\left(10^{18} \mathrm{~W}\right)$.

New classes of high fluence, high power damage resistant materials for optics and gratings will be required to successfully provide this capability on NIF. It is clear that further research leading to a better understanding of polishing processes of glass surfaces will continue to benefit development of optical glasses for high power lasers. Continued work on glass composition, glass chemical and physical properties, slurry chemistry, and material removal should dramatically advance our understanding of optical glass polishing and laser-induced damage for applications to petawatt class lasers and next-generation laser fusion facilities. 


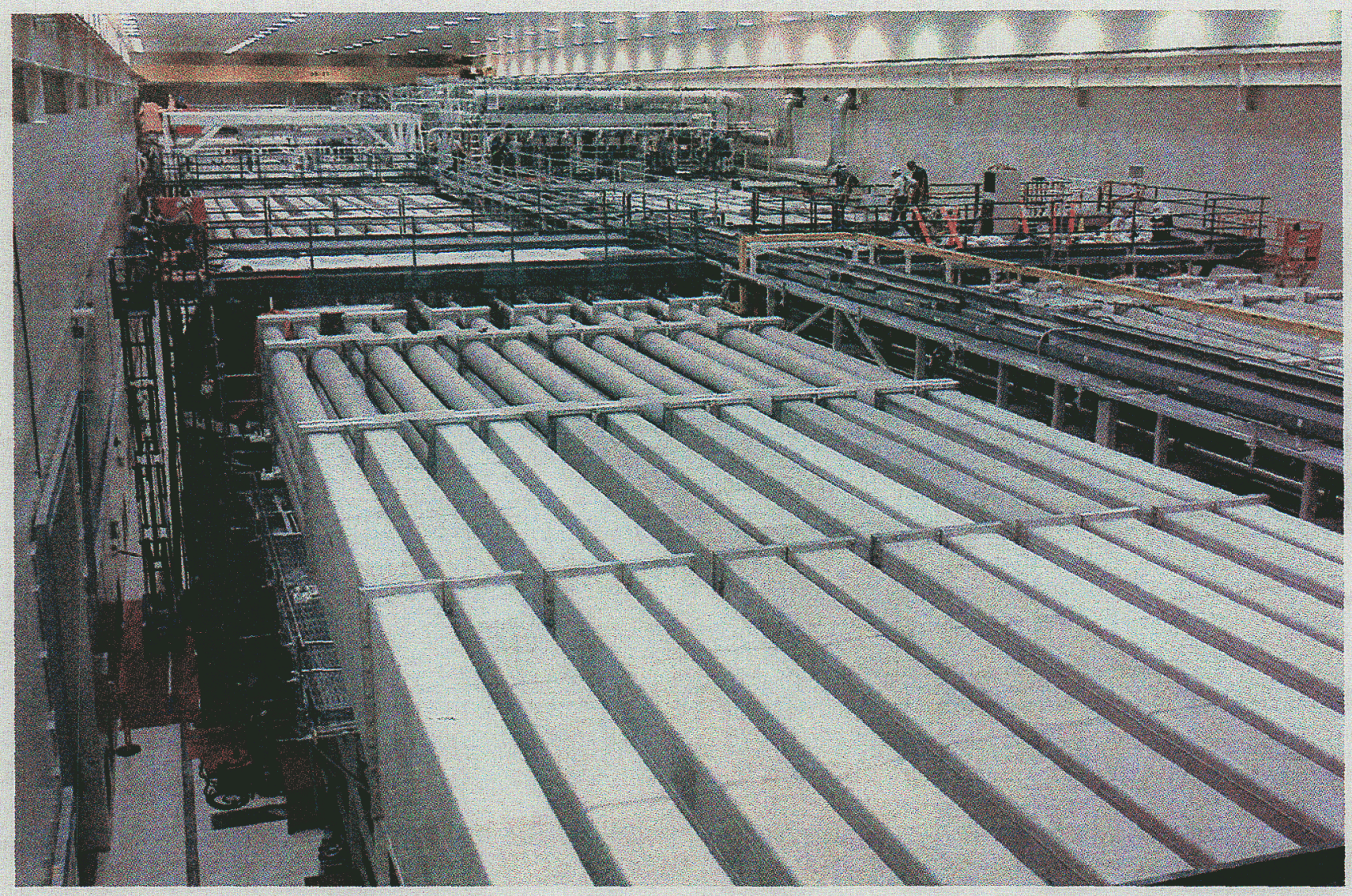

Figure 9: View of Laser Bay 2 that contains two "clusters" of 48 beams. The laser beams travel inside the beam-tubes that are prominent in the lower, center portion of the photo. Note that there are twelve flat-topped "tubes" visible across the photo; they comprise one of the clusters. Each tube consists of four independent laser beams stacked one-on-top-ofthe-other giving a $4 \times 12$ array of 48 beams (this is more clearly see where the square tubes mate with the round ones near the center of the photo). The two laser bays combined contain four clusters giving 192 beams total. Work is underway to complete Laser Bay 1 by mid 2003 while commissioning shots take place concurrently in Laser Bay 2. (The workers standing on the scaffolding in the upper right corner give a sense of the scale.)

\section{ACKNOWLEDGMENTS}

The authors gratefully acknowledge the many people, institutions, and industrial partners that are diligently working to build the National Ignition Facility. This work was performed under the auspices of the U.S. Department of Energy by the University of California, Lawrence Livermore National Laboratory under contract W-7405-Eng-48.

\section{REFERENCES}

[1] J. Lindl, Inertial Confinement Fusion: The Quest for Ignition and Energy Gain Using Indirect Drive, SpringerVerlag (1998).

[2] S. W. Haan, S. M. Pollaine, J. D. Lindl, L. J. Suter, R. L. Berger, L. V. Powers, W. E. Alley, P. A. Amendt, J. A. Futterman, W. K. Levendahl, M. D. Rosen, D. P. Rowley, R. A. Sacks, A. I. Shestakov, G. L. Strobel, M. Tabak, S. V. Weber, G. B. Zimmerman, W. J. Krauser, D. C. Wilson, S. Coggeshall, D. B. Harris,

N. M. Hoffman and B. H. Wilde, "Design and modeling of ignition targets for the National Ignition Facility", Phys. Plasmas, $\underline{2}$ (1995) p. 2480. 
[3] C. B. Tarter, "Inertial Fusion and Higher Energy Density Science in the United States," Proc. 2001 Conf. On Inertial Fusion Science and Applications (IFSA 2001), K. A. Tanaka, D. D. Meyerhofer, J. Meyer-ter-Vehn, eds., Elsevier (2002).

[4] S. Haan, et al., "Update On Target Design for the National Ignition Facility," Proc. 2001 Conf. On Inertial Fusion Science and Applications (IFSA 2001), K. A. Tanaka, D. D. Meyerhofer, J. Meyer-ter-Vehn, eds., Elsevier (2002).

[5] J. R. Murray, "Overview of the National Ignition Facility", Third Annual International Conference on Solid State Lasers for Application to ICF, SPIE Proceedings, Suppl. Vol. 3492 (1998), p. 1-10.

[6] "Solid State Lasers for Application to Inertial Confinement Fusion (ICF)," W. F. Krupke, ed., Proc. SPIE 2633 (1995).

[7] J. T. Hunt and D. R. Speck, "Present and future performance of the Nova laser system", Opt. Eng., 28 (1989) p. 461.

[8] T. R. Boehly, D. L. Brown, R. S. Craxton, R. L. Keck, J. P. Knauer, J. H. Kelly, T. J. Kessler, S. A. Kumpan, S. J. Loucks, F. J. Marshall, R. L. McCrory, S. F. B. Morse, W. Seka, J. M. Souers, C. P. Verdon, “The Omega upgade laser system", Opt. Commun., 133 (1997) p. 495.

[9] B. Remington, "High Energy Density Astrophysics in the Laboratory," Proc. 2001 Conf. On Inertial Fusion Science and Applications (IFSA 2001), K. A. Tanaka, D. D. Meyerhofer, J. Meyer-ter-Vehn, eds., Elsevier (2002).

[10] "High-Energy-Density Physics Study Report," prepared by the National Nuclear Security Administration Office of Defense Programs, April 6, 2001.

[11] "National Ignition Facility Title I Design and Title II Activities", J. R. Murray Ed., Inertial Confinement Fusion Quarterly Report, LLNL Report UCRL-LR-105821-97-3 (1997) p. 1-222.

[12] J. H. Campbell and T. I. Suratwala, "Nd-doped phosphate glasses for high-energy/high-peak-power lasers", J. Non-Cryst. Solids, 263\&264 (2000) p. 318-341.

[13] M. A. Rhodes, B. Woods, J. J. DeYoreo, D. Roberts, and L. J. Atherton, "Performance of large-aperture optical switches for high-energy ICF lasers", Appl. Opt. 34, 5313-5330 (1995).

[14] J. Goldhar and M. A. Henesian, "Large-aperture electrooptical switches with plasma electrodes", IEEE J. Quantum Electron. QE22, 1137-1147 (1986).

[15] "Optics Technology for the National Ignition Facility", J. Atherton Ed., Inertial Confinement Fusion Quarterly Report, LLNL Report UCRL-LR-105821-99-2 (1999) p. 1-212.

[16] B. M. Van Wonterghem, J. R. Murray, J. H. Campbell, D. R. Speck, C. E. Barker, I. C. Smith, D. F. Browning and W. C. Behrendt, "Performance of a prototype for a large-aperture multi-pass Nd:glass laser for inertial confinement fusion", Appl. Opt., 36 (1997) p. 4932.

[17] J. H. Campbell, T. I. Suratwala, C. B. Thorsness, J. S. Hayden, A. J. Thorne, J. M. Cimino, A. J. Marker III, K. Takeuchi, M. Smolley, and G. F. Ficini-Dorn, "Continuous melting of phosphate laser glasses", J. Non-Cryst Solids, 263\&264 (2000) p. 342-357.

[18] C. B. Thorsness, T.I. Suratwala, R.A. Steele, J. H. Campbell, J. S. Hayden, S. A. Pucilowski, K. Suzuki, "Dehydroxylation of Phophate laser glass", SPIE Proceedings, 4102 (2000) p175-194.

[19] C. J. Stolz, J. A. Menapace, M. R. Borden, A. Slomba, C. Kiikka and S. Gelman, "Status of optical finishing for the National Ignition Facility", in Optical Fabrication and Testing, OSA Technical Digest (2002), p. 67-69.

[20] T. G. Parham, C. J. Stolz, T. Baisden, M. Kozlowski, C. Kiikka and D. M. Aikens, "Developing optics finishing technologies for the National Ignition Facility", ICF Quarterly Report, 9 (1999), p. 177-191; LLNL Report UCRL-LR-105821-99-20.

[21] J. J. DeYoreo, A. K. Burnham, and P. K. Whitman, "Developing $\mathrm{KH}_{2} \mathrm{PO}_{4}$ and $\mathrm{KD}_{2} \mathrm{PO}_{4}$ crystals for the world's most power laser", International Materials Review 47 (2002) p. 113-152.

[22] M. R. Kozlowski "Damage-resistant laser coatings," in Thin Films for Optical Systems, Marcel Dekker, Flory FR (ed), New York, pp 521-549 (1995).

[23] C. J. Stolz, and F. Y. Génin, "Laser resistant coatings," in Optical Interference Coating, Springer Series in Optical Sciences, Eds. N. Kaiser and H. Pulker, Springer, in press.

[24] J. B. Oliver, J. Howe, A. Rigatti, D. J. Smith and C. J. Stolz, "High precision coating technology for large aperture NIF optics," in Optical Interference Coatings, OSA Technical Digest (Optical Society of America, Washington DC), pp. ThD2-1 - ThD2-3, (2001). 
[25] C. J. Stolz, C. L. Weinzapfel, G. T. Rogowski, D. J. Smith, A. Rigatti, J. Taniguchi, M. Von Gunten, R. P. Bevis, M. Smith and V. Ivan, "Status of optical coatings for the National Ignition Facility," in Optical Interference Coatings, OSA Technical Digest (Optical Society of America, Washington DC), pp. ThD3-1 - ThD3-3, (2001).

[26] T. I. Suratwala, M. L. Hanna, E. L. Miller, P. K. Whitman, I. M. Thomas, P. R. Ehrmann, R. S. Maxwell and A. K. Burnham, J. Non-Crystal. Solids, 316 (2003) p. 349-363.

[27] S. Schwartz, R. T. Jennings, J. F. Kimmons, R. P. Mouser, C. L. Weinzapfel, M. R. Kozlowski, C. J. Stolz, and J. H. Campbell, "Vendor-based laser damage metrology equipment supporting the National Ignition Facility," in Solid State Lasesr for Application to Inertial Confinement Fusion, W. Howard Lowdermilk, editor, Proc. SPIE 3492, 933-938, (1999).

[28] J. K. Lawson, D. M. Aikens, R. E. English, Jr., W. T. Whistler, W. House, M. A. Nichols, "Surface figure and roughness tolerances for NIF optics and the interpretation of the gradient, P-V wavefront, and RMS specifications," in Optical Manufacturing and Testing III, H. Philip Stahl, Editor, Proceedings of SPIE Vol. 3782, 510-517 (1999).

[29] J. H. Campbell, "Damage Resistant Optical Glasses for High Power Lasers: A Continuing Glass Science and Technology Challenge," Proceedings of the First International Workshop on Glass and the Photonics Revolution, May 28-29, 2002, Bad Soden, Germany (in press).

[30] J. Campbell and F. Rainer, "Optical glasses for high-peak-power applications", SPIE Proceedings, Vol. 1761 (1992) p. 246-255.

[31] J. H. Campbell, F. Rainer, M. Kozlowski, C. Wolfe, I. Thomas and F. Milanovich, "Damage resistant optics for a megajoule solid-state laser", SPIE Proceedings, Vol. 1441 (1991), p. 444.

[32] A. K. Burnham, L. Hackel, P. Wegner, T. Parham, L. Hrubesh, B. Penetrante, P. Whitman, S. Demos, J. Menapace, M. Runkel, M. Fluss, M. Feit, M. Key and T. Biesiada, "Improving 351-nm damage performance of large-aperture fused silica and DKDP optics", SPIE Proceedings, Vol. 4679 (2002) p. 173-185.

[33] Proceedings from the annual meetings on "Laser-induced Damage in Optical Materials", 1971 to 2001, available from SPIE.

[34] B. C. Stuart, M. D. Feit, A. M. Rubenchik, B. W. Shore and M. D. Perry, "Laser-induced damage in dielectrics with nanosecond to sub-picosecond pulses", Phys. Review Lett., 74 (1995) p. 2248-51.

[35] J. H. Campbell, E. P. Wallerstein, J. S. Hayden, D. L. Sapak, D. E. Warrington, A. J. Marker, H. Toratani, H. Meissner, S. Nakajima and T. Izumitani, "Elimination of platinum inclusions in phosphate laser glasses", Lawrence Livermore National Laboratory Report UCRL-53932, 1989.

[36] J. H. Campbell, E. P. Wallerstein, J. S. Hayden, D. L. Sapak, D. E. Warrington, A. J. Marker, “ Effects of melting conditions on platinum-inclusion content in phosphate laser glasses", Glastech. Ber. Glass Sci. Technol., $\underline{68}$ (1995), p. 11.

[37] J. H. Campbell, E. P. Wallerstein, H. Toratani, H. E. Meissner, S. Nakajima and T. S. Izumitani, "Effects of process gas environment on platinum-inclusion density and dissolution rate in phosphate laser glasses", Glastech. Ber. Glass Sci. Technol., $\underline{68}$ (1995), p. 59.

[38] J. H. Campbell, "Modeling platinum inclusion dissolution in phosphate laser glasses", Glastech. Ber. Glass Sci. Technol., 68 (1995) p. 96.

[39] M. S. Dobbins and R. E. McLay, "Method for making fused silica by decomposing siloxanes", U.S. Patent No. 5,043,002, Aug. 27, 1991.

[40] M. R. Kozlowski, R. Mouser, S. Maricle, P. Wegner, and T. Weiland, "Laser damage performance of fused silica optical components measured on the Beamlet laser at 351-nm", SPIE Proceedings, Vol. 3578 (1999), p. 436-443.

[41] "Synthetic Fused Silica: Optical and Technical Grades", Product Catalogue (2002), Schott Lithotec A.G., 55130 Mainz, Germany.

[42] “Heraeus Quartz: Fused Quartz and Fused Silica for Optics", Product Catalogue 40-1015-079, Herasil Amersil Inc., Buford, GA.

[43] M. R. Kozlowski, J. Carr, I. Hutcheon, R. Torres, L. Sheehan, D. Camp and M. Yan, "Depth profiling of polishing-induced contamination on fused silica surfaces", SPIE Proceedings, Vol. 3244 (1998), p. 365-375.

[44] S. G. Demos, M. C. Nostrand, M. Staggs, C. W. Carr, D. Hahn, M. R. Kozlowski, L. Sheehan, C. Battersby and A. Burnham, "Investigation of fluorescence microscopy as a tool for noninvasive detection and imaging of damage precursors at 351-nm", SPIE Proceedings, Vol. 4679 (2002), p. 347-359.

[45] F. Genin, A. Salleo, T. Pister and L. Chase, "Role of light intensification by cracks in optical breakdown on surfaces", J. Opt. Soc. Amer. A, 18 (2001), p. 2607-2616. 
[46] M. A. Norton, L. W. Hrubesh, Z. Wu, E. Donohue, M. D. Feit, M. R. Kozlowski, D. Milam, K. P. Neeb, W. A. Molander, A. M. Rubenchik, W. D. Sell and P. Wegner, "Growth of laser initiated damage in fused silica at 351-nm", SPIE Proceedings, Vol. 4347 (2001), p. 468.

[47] D. Golini, S. Jacobs, W. Kordonski and P. Dumas, "Precision optics fabrication using magnetorheological finishing”, Advanced Materials for Optics and Precision Structures, CR67 (1997), 251-274.

[48] S. D. Jacobs, D. Golini, Y. Hsu, B. E. Puchebner, D. Strafford, W. I. Kordonski, I. V. Prokhorov, E. Fess, D. Pietrowski and V. W. Kordonski, "Magnetorheological finishing: a deterministic process for optics manufacturing", SPIE Proceedings, Vol. 2576 (1995), p. 372-382.

[49] S. D. Jacobs, F. Yang, E. M. Fess, J. B. Feingold, B. E. Gillman, W. I. Kordonski, H. Edwards and D. Golini, "Magnetorheological finishing of IR materials", SPIE Proceedings, Vol. 3134 (1997), p. 258-269.

[50] S. R. Arrasmith, I. A. Kozhinova, L. L. Greg, A. B. Shorey, H. J. Romanofsky, S. D. Jacobs, D. Golini, W. I. Kordonski, S. Hogan and P. Dumas, "Details of the polishing spot in magnetorheological finishing", SPIE Proceedings, Vol. 3782 (1999), p. 92-100.

[51] D. Golini, W. I. Kordonski, P. Dumas and S. Hogan, "Magnetorheological finishing (MRF) in commercial precision optics manufacturing", SPIE Proceedings, Vol. 3782 (1999), p. 80-91.

[52] J. A. Menapace, B. Penetrante, D. Golini, A. Slomba, P. E. Miller, T. Parham, M. Nichols and J. Peterson, "Combined advanced finishing and UV laser conditioning for producing UV-damage-resistant fused silica optics", SPIE Proceedings, Vol. 4679 (2002), p. 56-68.

[53] M. Kozlowski, C. Wolfe, M. Staggs and J. Campbell, "Large-area laser conditioning of dielectric thin film mirrors", SPIE Proceedings, Vol. 801 (1990), p. 376-392.

[54] L. J. Atherton, F. Rainer, J. J. DeYoreo, I. M. Thomas, N. Zaitseva and F. DeMarco, "Thermal and laser conditioning of production and rapid-growth KDP and KD*P crystals”, SPIE Proceedings, Vol. 2114 (1994), p. 36-44.

[55] M. Runkel, K. Neeb, M. Staggs, J. Auerbach and A. Burnham, "The results of raster-scan laser conditioning studies on DKDP triplers using Nd:YAG and excimer lasers”, SPIE Proceedings, Vol. 4679 (2002), p. $368-383$.

[56] R. M. Brusasco, B. M. Penetrante, J. E. Peterson, S. M. Maricle and J. Menapace, "UV laser conditioning for reduction of 351-nm damage initiation in fused silica", SPIE Proceedings, Vol. 4679 (2002), p. 48-55.

[57] R. M. Brusasco, B. M. Penetrante, J. A. Butler and L. W. Hrubesh, "Localized $\mathrm{CO}_{2}$ laser treatment for mitigation of 351-nm damage growth on fused silica", SPIE Proceedings, Vol. 4679 (2002), p. $40-47$. 